\title{
Effect of sowing date and crop spacing on growth, yield attributes and quality of sesame
}

\author{
K. Sivagamy ${ }^{1}$ and J. Rammohan ${ }^{2}$ \\ 1,Department of Agronomy, Adhiparasakthi Agricultural, Horticultural College and Research Institute, \\ G.B.Nagar, Kalavai, Vellore \\ 2,Professor,Department of Agronomy ,Pandit Jawaharlal Nehru College of Agriculture and Research \\ Institute, Karaikal
}

\begin{abstract}
Sesame is one of the oldest and most important oil seed crop. This study was carried out to determine the effects of different sowing dates and inter-and intra-row spacings on the growth and yield components on sesame. A Field experiment was conducted during summer season of 2006 (Masipattam) to evaluate the optimum time of sowing and spacing for realizing higher seed yield. The experiment was laid out in randomized block design (RBD) with six replications. The treatments consisted of two factors: (i) time of sowing (second fortnight of February and first fortnight of March) and (ii) crop geometries (30 $\times 30 \mathrm{~cm}, 45 \times 15 \mathrm{~cm}, 30 \times 10 \mathrm{~cm}$ and $15 \times 10 \mathrm{~cm}$ ). The results of the experiment field revealed that performance of test variety of KS 95010 was superior when sown early during the second fortnight of February (Masipattam) in the rectangular geometry of $45 \times 15 \mathrm{~cm}$ under irrigated condition in the karaikal region.
\end{abstract}

Key words: Sesame, time of sowing, geometry, growth, yield and oil content

\section{Introduction}

SESAME (Sesamum indicum L.) is one of the oldest crops in the world under cultivation in Asia for over 5000 years [1]. The crop has early origins in East Africa and in India. Today, India and China are the world's largest producers of sesame followed by Myanmar, Sudan, Uganda, Nigeria, Pakistan, Tanzania, Ethiopia, Guatemala and Turkey. The crop is highly drought tolerant, grows well in most kind of soils, regions and is well suited to different crop rotations. In reality, sesame is mostly grown under moisture stress with low management input by small holders [2] . Among the oilseed crops, sesame ranks first for having the highest oil content of 46-64 per cent and $6355 \mathrm{~K} \mathrm{cal} \mathrm{kg}^{-1}$ dietary energy in seeds [3] Sesame oil with 85 per cent unsaturated fatty acid is highly stable and has reducing effect on cholesterol and prevents coronary heart disease. Hence, sesame is called as the "Queen of oil seeds" by virtue of its excellent quality and utility. Sesame is one of the important crop included in the cropping system of this region as rice-fallow crop. Selection of suitable variety, time of sowing, appropriate geometry and agronomic technologies are paramount importance for increasing the productivity of sesame in this region.

\section{Materials And Methods}

A field experiment was conducted at 2006 during summer season (February, March: Masipattam) at experimental farm of the Department of Agronomy, Pandit Jawaharlal Nehru College of Agriculture and Research Institute, Karaikal. The experiment was laid out in a randomized block design with six replications. The soil of the experiment field was sandy loam in texture with a pH of 7.4, EC of $0.23 \mathrm{dSm}^{-1}$, the fertility status of the soil was low in available nitrogen $\left(216 \mathrm{~kg} \mathrm{ha}^{-1}\right)$, medium in available phosphorous $\left(14 \mathrm{~kg} \mathrm{ha}^{-1}\right)$ and medium in available potassium $\left(144 \mathrm{~kg} \mathrm{ha}^{-1}\right)$. The treatment details were factor I - Time of sowing T1 = II Fortnight of February, $\mathrm{T}_{2}=\mathrm{I}$ Fortnight of March and factor II - Crop geometries $\mathrm{G}_{1}=30 \mathrm{X} 30 \mathrm{~cm}, \mathrm{G}_{2}=45 \mathrm{X} 15$ $\mathrm{cm}, \mathrm{G}_{3}=30 \times 10 \mathrm{~cm}, \mathrm{G}_{4}=15 \times 10 \mathrm{~cm}$. The experiment was conducted with $\mathrm{KS} 95010$ as test variety with a fertilizer dose of 35:23:23 $\mathrm{kg} \mathrm{NPK} \mathrm{ha}^{-1}$.

\section{Growth attributes}

\section{Results And Discussion}

The plant height observed on 20 DAS had shown unequivocally a significant difference between the two different time of sowings by registering the tallest plants when sown during the second fortnight of February $\left(T_{1}\right)$ than delayed sowing at the first fortnight of March $\left(T_{2}\right)$ in both the years $(15.0$ and $14.4 \mathrm{~cm})$. At subsequent stages of 40,60 and 80 DAS same trend was observed.Among the four geometry levels tried, sowing of sesame at wider spacing of $45 \times 15 \mathrm{~cm}\left(\mathrm{G}_{2}\right)$ exhibited significantly the tallest plants of 17.3, 59.8, 96.0 and $108.4 \mathrm{~cm}$ in the first year at four stages of observation.. The lowest plant height of 10.9, 34.0, 64.7 and $74.2 \mathrm{~cm}$ were noticed under the closer spacing $(15 \times 10 \mathrm{~cm})$. The wider geometry might have provided sufficient 
rooting and moisture extraction pattern to the optimum plant population $\left(14 \mathrm{~m}^{-2}\right)$ which in turn would have helped better absorption of water and nutrients from the soil resulting in tallest plants during both the years. This is in agreement with the findings [4] (Table 1).

The interaction effect between the time of sowing and crop geometry had shown a non-significant influence on plant height was discremible at 20,60 and 80 DAS except at 40 DAS in the first year, which had showed a significant influence on plant height. Delayed sowing at the first fortnight of March registered shortest plant height. This may be due to the congenial climatic condition prevailed from its early growth stage which might have helped the plants to put forth enhanced rate of growth and development. A similar finding was reported earlier by [5] .

Early sowing helped the sesame plants to achieve higher LAI as compared to delayed sowing. Highest leaf area index was observed in closer spacing of $15 \times 10 \mathrm{~cm}\left(\mathrm{G}_{4}\right)$ at 60 DAS was $2.21 \mathrm{~cm}$. The increase in LAI under closer spacing throughout the growth period was due to more number of leaves per unit area which in turn was due to increased number of plants per unit area, results are in accordance with the findings of [6]. Sowing of sesame, at second fortnight of February i.e. $26^{\text {th }}$ February had more dry matter accumulation during summer season than the delayed sowing.

\section{Yield attributes and yield}

The early sowing of sesame culture (KS 95010) at $26^{\text {th }}$ Feb during second fortnight February exhibited significant influence on primary and secondary branches plant ${ }^{-1}$ at 40 and 60 DAS during summer 2006. The same treatment has recorded more number of primary branches (4.5 and 5.3) at 40 and 60 DAS, respectively. The mean number of primary and secondary branches plant ${ }^{-1}$ significantly decreased by even one week delay in the date of sowing. Wider spacing of $45 \times 15 \mathrm{~cm}$ recorded significantly higher values of primary $(157 \%)$ and secondary $(148 \%)$ branches at harvest stage over closer spacing $(15 \times 10 \mathrm{~cm})$ during the season. The wider planting geometry of $45 \times 15 \mathrm{~cm}$ enhanced the primary and secondary branches over remaining geometries owing to better geometric arrangement, resulting in better absorption of moisture and nutrients due to lesser competition for growth factors between plants. Similar findings were also observed by [7].

Significantly higher number of capsules $\mathrm{m}^{-2}$ was observed in early sowing than delayed sowing. Among the different spacings wider spacing of $45 \times 15 \mathrm{~cm}$ registered higher capsule number $\mathrm{m}^{-2} 26$ per cent over closer spacing of $15 \times 10 \mathrm{~cm}$ and 2.5 per cent over the next best geometry of $30 \times 30 \mathrm{~cm}$. This might be due to relatively lesser inter-plant competition for space, light, nutrient and moisture etc. Further, owing to better geometric arrangement, the above factors would have also helped in enhanced photosynthetic rate which consequently might have manifested higher number of capsules $\mathrm{m}^{-2}$. The results fall in line with the observation of [8]

Time of sowing failed to exert any significant influence on the number of seeds capsule ${ }^{-1}$. Higher number of seeds capsule ${ }^{-1}$ was recorded at wider spacing of $45 \times 15 \mathrm{~cm}$ with 11 per cent increase over closer spacing $(15 \times 10 \mathrm{~cm})$. It could be ascribed to over all improvement in plant vigour and production of sufficient photosynthates through increased LAI and higher DMP with better partitioning might have increased the number of seeds capsule $e^{-1}$ accordance with the findings of [9]. The test weight of sesame differed significantly due to times of sowing. Early sowing recorded higher test weight (4\%) than delayed sowing. Wider spacing of $45 \times 15 \mathrm{~cm}$ recorded higher test weight than closer spacing of $15 \times 10 \mathrm{~cm}$ difference during the summer season. Test weight was governed by the genetic make up, of the variety KS 95010 possesses the characteristic feature of producing more number of seeds with enhanced seed size under the ideal environment [10] .

Early sowing date of $26^{\text {th }}$ February during second fortnight of February recorded higher seed yield of $760 \mathrm{~kg} \mathrm{ha}^{-1}$ during 2006 than delayed sowing at first fortnight of March. Wider spacing of $45 \times 15 \mathrm{~cm}$ recorded significantly higher seed yield of $908 \mathrm{~kg} \mathrm{ha}^{-1}$ during 2006 was followed by normal spacing of $30 \times 30 \mathrm{~cm}$ with $800 \mathrm{~kg} \mathrm{ha}^{-1}$. The lower seed yield was obtained at a closer spacing of $15 \times 10 \mathrm{~cm}$ was recorded $548 \mathrm{~kg} \mathrm{ha}^{-1}$. Early sowing (on $26^{\text {th }}$ February) recorded higher seed yield than delayed sowing may be attributed for favourable climatic conditions, less pest and disease occurence, harnessing of more solar radiation as evidenced through larger LAI, higher DMP and higher values for all the yield contributing traits which in turn has increased the seed yield. This results is in line with the findings of Tripathi et al. (1998). The optimum plant density $\left(14\right.$ plants $\mathrm{m}^{-2}$ ) under wider spacing of $45 \times 15 \mathrm{~cm}$ would have efficiently utilized all the resources to result in increased oil content over other geometries tested.

\section{Conclusion}

From the results of the study concluded, performance of pre-release sesame culture (KS 95010) was superior when sown early during the second fortnight of February (Masipattam) in the rectangular geometry of $45 \times 15 \mathrm{~cm}$ under irrigated condition in the Cauvery delta zone. This combination registered a net income of Rs. 19,801 with B:C ratio of 3.09. This gives an option to conclude that sowing during the second fortnight of 
February in the rectangular geometry of $45 \times 15 \mathrm{~cm}$ as an ideal agronomic practice for improving the sesame productivity with maximum gross income, net income and B:C ratio in Cauvery delta zone of Karaikal.

\section{References}

[1] Bisht, I.S, Mahajan Loknathan ,T.R and Agrawal, RC. 1998. Diversity in Indian sesame collection and stratification of germplasm accessions in different diversity groups. Genet Resour Crop Evol. 45: 325-335.

[2] Cagurgan ,M.I. 2006. Selection and morphological characterization of induced determinate mutants in sesame.Field Crops Res. 96: $19-24$

[3] Sanjay Kumar, S. and Goel, P.D. 1994. A great ancient oilseed-sesamum. Farmer and Parliament, 12:6-7.

[4] Chimanshette, T. G., Dhoble , M. V. and Balasubramaniyan, P. 1996. Influence of plant population and nitrogen on yield and nutrient response of sesame (Sesamum indicum). Indian J. Agron.,41(3): 448-450.

[5] Muthusankaranarayanan, A., Anandkumar ,S. and Pandian, B. J. 2001. Optimum time of sowing and nitrogen management for summer irrigated sesame. Sesame and safflower Newsletter, 16: 64 -67.

[6] Ghosh, D. C. and Patra,A.K.1994.Effect of plant density and fertility levels on productivity and economics of summer sesame (Sesamum indicum L.). Indian J. Agron., 39(1): 71-75.

[7] Mujaya, I. M. and Yerokun, O. A. 2003.Response of sesame to plant population and nitrogen fertilizer in north-central Zimbabwe. Sesame and Safflower Newsletter, No.18.

[8] Subrahmaniyan, K., Arulmozhi ,N and Kalaiselvan,P. 2001. Influence of plant density and NPK levels on the growth and yield of sesame (Sesamum indicum) genotypes. Agric. Sci. Digest, 21(3): 210-212

[9] Ramanathan, SP. and B. Chandrasekharan. 1998. Effect of clipping, plant geometry and fertilizer on summer sesame (Sesamum indicum L.). Indian J. Agron., 43(2): 329-332.

[10] Govindarasou, R., P. Sivasubramanian and K. Manian. 1998. Analysis of seed yield and yield component in sesame at coastal Karaikal. J. Indian Soc. Coastal Agric. Res. 7(2): 95 - 97. 